\title{
Application of Y-Aminobutyric Acid Treatment Differently Affects Physicochemical Characteristics of Tomato Fruits during Post-harvest Storage
}

\section{Selman ULUIŞIK ${ }^{1}$}

${ }^{1}$ Burdur Mehmet Akif Ersoy University, Burdur Food Agriculture and Livestock Vocational School, 15030 Burdur, Turkey

\section{Article History}

Received 13 July 2021

Accepted 16 September 2021

First Online 28 September 2021

Corresponding Author

E-mail: suluisik@mehmetakif.edu.tr

Keywords

Cell wall

GABA

Soluble pectin

Softening

Tomato

\begin{abstract}
The quality of tomato fruit, from harvest to human consumption, requires a lengthy period for shipping, storing, and marketing. $Y$-aminobutyric acid (GABA) is a good candidate because it is a natural substance produced by plants to defend themselves against stress conditions. In this study, the effect of post-harvest GABA treatments at 0 (control), $5 \mathrm{mM}$ and, $20 \mathrm{mM}$ on the physical and biochemical properties and the polysaccharide content of tomatoes during 28 days of storage were investigated. Our results indicated that $5 \mathrm{mM}$ of GABA treatment increased firmness and shelf-life by maintaining the integrity of fruits compared to control and $20 \mathrm{mM}$ of GABA treated fruits. The fruits treated with $5 \mathrm{mM}$ of GABA decreased the amount of WSP and the expression of cell wall related genes Pectate lyase $(P L)$ and Polygalacturonase $(P G)$. There was not a clear difference in colour index $(\mathrm{Cl})$ values among all treated groups at the end of post-harvest storage. Moreover, the tomato fruits treated with $5 \mathrm{mM}$ GABA also showed somewhat less ethylene production, respiration rate and expression level of two ethylene synthesis genes ACS2 and ACS4 towards the end of storage. These results suggested that treatment with $5 \mathrm{mM}$ GABA could be a beneficial strategy for maintaining the morphological and biochemical quality of tomato under postharvest storage conditions.
\end{abstract}

\section{Introduction}

Tomato (Solanum lycopersicum L.) is an important agricultural crop because of its great nutritive and commercial value. It is one of the most widely produced and consumed vegetable crops with over 180 million tonnes of production and a $\$ 190.4$ billion commercial value (FAO, 2019). Moreover, tomato is a model species for studying processes such as fruit development, fruit ripening and post-harvest storage conditions (Giovannoni, 2007), because of its relatively short life cycle, highquality with a modest reference genome (approximately $950 \mathrm{Mb}$ ), stable genetic transformability and availability of different ripening phenotypes (Klee and Giovannoni, 2011; Wang et al., 2018). The tomato has a relatively short post- harvest shelf life, which limits its transportability and marketability due to its rapid softening rate in postharvest storage conditions. During storage and transportation, ripening proceeds with a colour change from green to red, as well as softening and compositional changes in taste and aroma-related compounds such as organic acids, sugars, and volatiles (Park et al., 2021). Later stages of ripening/softening are usually accompanied by significant changes in texture resulting from the separation of the cell wall and middle lamellae, as well as water loss by transpiration (Seymour et al., 2013; Uluisik et al., 2016). To overcome the problem of accelerated softening, tomato fruits are usually harvested at the mature green or breaker stage (Wang et al. 2018). Alternatively, novel postharvest treatments have been investigated to delay 
tomato fruit ripening and to extend its shelf-life such as application of aminoethoxyvinylglycine (AVG) (Candir et al., 2017), hydrogen sulfide $\left(\mathrm{H}_{2} \mathrm{~S}\right.$ ) (Zhong et al., 2021) and UV-C (Mansourbahmani et al., 2018). These chemicals and/or technologies control the transpiration, respiration, ripening of fruits by regulating the biochemical changes in fruits, which delay internal ethylene synthesis in fruits and prolong the market availability of fruits.

Reactive oxygen species (ROS) are composed of several free radical-containing molecules that are regularly found in plants (Foyer et al., 2018) which are harmless when at normal levels. Studies have shown that ROS are key regulators that mediates signalling molecules at low concentrations to trigger defensive responses in fruits and developmental processes (Decros et al., 2019). Nevertheless, under stress conditions or during fruit ripening/softening process the level of ROS in fruits may exceed a certain threshold, which can cause irreversible DNA damage and cell death, resulting in senescence and reduced shelf life of fresh fruits (Chen et al., 2019; Lin et al., 2020). During postharvest storage life in unfavourable conditions may ascribe to triggering higher ROS accumulation accompanying senescence which deteriorates fruit quality (Lin et al., 2018). Therefore, the use of signalling antioxidant $\gamma$-aminobutyric acid (GABA) and molecules, which are key for reducing oxidative stress, may be beneficial in delaying senescence along with preserving sensory and nutritional quality of cherry fruits during post-harvest life (Aghdam et al., 2019; Li et al., 2019; Zarei et al., 2020; Niazi et al., 2021). GABA is a ubiquitous non-protein amino acid produced by glutamate decarboxylation and approved for use in food production in the United States and Europe (Yan et al., 2016). Although under normal growing conditions, GABA content of most plants is relatively low, its accumulation in plant tissues is induced after exposure to various stresses (Kinnersley and Turano, 2000). Moreover, exogenous post-harvest treatment of GABA maintained membrane integrity, delayed browning/softening and preserved nutritional quality (Aghdam et al., 2019; Nazoori et al., 2020). In this study, we aimed to investigate the effect of GABA treatment on tomato softening in post-harvest storage. To achieve this goal, pectin fractionation, gene expression of key pectin-degrading enzymes, ethylene and respiration rates of fruits were evaluated in tomato fruits treated with two different GABA concentrations.

\section{Materials and Methods}

\subsection{Plant material and GABA treatment}

Tomato fruits (S. lycopersicum L. cv. Verty F1) were grown in a glasshouse, Akdeniz University, Antalya, Turkey, at controlled temperatures of 28$33^{\circ} \mathrm{C}$ during the day and $20-26^{\circ} \mathrm{C}$ at night, $85 \%$ relative humidity and photoperiod of 12 to 13 hours. Fruits of uniform size that were free from physical defects were harvested at the mature green stage and transported to the laboratory within 2 hours. Fifty-fruits were used for each treatment.

Based on previous studies (Kinnersley and Turano, 2000; Deewatthanawong et al., 2010; Shang et al. 2011; Malekzadeh et al., 2014; Soleimani Aghdam et al., 2016), solutions of GABA (Sigma-Aldrich Co.) at a concentration of $5 \mathrm{mM}$ and $20 \mathrm{mM}$ were selected as the most suitable concentrations. All fruits were immersed in GABA solutions for 30 minutes and then air-dried directly at room temperature. Only distilled water was used for the control fruits. All fruits were stored in plastic trays at room temperature $\left(25 \pm 2^{\circ} \mathrm{C}\right)$ and $60 \pm 5 \%$ relative humidity and analyzed for 28 days at seven days intervals. Half of the analyzed fruits were immediately frozen in liquid nitrogen, and then keep at $-80^{\circ} \mathrm{C}$ for biochemical analysis and RNA isolation.

\subsection{Determination of fruit colour, firmness, and fruit weight loss}

Ten fruits were selected for each treatment group to measure fruit colour. The same fruits were used to measure colour of fruits throughout the experiment. Two symmetrical positions around the equator on each fruit were measured with a colourmeter (PCE-CSM 1) and recorded as Hunter's L*, a*, and $b^{*}$ values. The colour measurements of tomato fruits were carried out twice a week at interval of 3 and 4 days. The colour index $(\mathrm{Cl})$ values were calculated according to (Nangare et al., 2016). The average of the maximum forces was recorded from the pericarp of five different fruits for each treatment and each week (PCE-PTR 200 penetrometer) to represent fruit firmness at the ripening stages. Fruit weight loss (FWL) was calculated as the percentage difference between the initial (harvested) and at 7day intervals until 28 days after harvesting (DAH) of the fruits and calculated according to the following equation: FWL $(\%)=(D A H 28 /(D A H 0-1) \times 100$. In this process, morphological changes in the fruits were also photographed.

\subsection{Determination of respiration rates and ethylene production}

The respiration rate of fruits determined with gas chromatography (GC) (Thermo Finnigan Trace GC Ultra, Thermo Electron S.p.A. Strada Rivoltana 20900 Radano, Milan, Italy). For the measurement tomatoes were stored in $2 \mathrm{~L}$ gas-tight jars for $1 \mathrm{~h}$ at $20^{\circ} \mathrm{C}$. Then a $1 \mathrm{~mL}$ gas sample was taken from the head space of jars and injected into GS equipped with a thermal conductivity detector. The results were calculated as $\mathrm{mL} \mathrm{CO}_{2} \mathrm{~kg}^{-1} \mathrm{~h}^{-1}$. Chromatographic conditions of respiration rate measurement were as follows: $80 / 100$ Porapak-Ncolumn, $65^{\circ} \mathrm{C}$ oven temperature, $100^{\circ} \mathrm{C}$ detector temperature, $100^{\circ} \mathrm{C}$ injection temperature, 


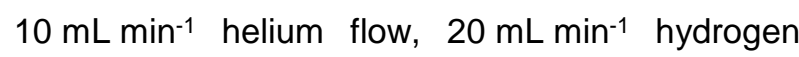
flow, $30 \mathrm{~mL} \mathrm{~min}^{-1}$ nitrogen flow and 4 min analysis time.

The ethylene production was determined by sealing five fruits in a $2 \mathrm{~L}$ gas-tight jars for $1 \mathrm{~h}$ at $20^{\circ} \mathrm{C}$. Then a $1 \mathrm{~mL}$ of gas sample was taken from the head space of jars and injected into GS equipped with a flame ionization detector. The results were calculated as $\mu \mathrm{L} \mathrm{C}_{2} \mathrm{H}_{4} \mathrm{~kg}^{-1} \mathrm{~h}^{-1}$. Chromatographic conditions of ethylene production measurement were as follows: $80 / 100$ alumina $f-1$ column, $90^{\circ} \mathrm{C}$ oven temperature, $170^{\circ} \mathrm{C}$ detector temperature, $150^{\circ} \mathrm{C}$ injection temperature,

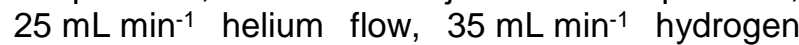
flow, $350 \mathrm{~mL} \mathrm{~min}{ }^{-1}$ nitrogen flow and 2 min analysis time.

\subsection{Extraction and fractionation of cell wall components}

The production df colourless alcohol-insoluble solids (AIS) and analysis of the cell wall composition were carried out according to the method described above (Lunn et al., 2013). The methodology of Filisetti-Cozzi and Carpita (1991) was followed for quantification of uronic acids and results were expressed as GA (galacturonic acid) $\mathrm{mg} \mathrm{g}^{-1}$ of AIS. Samples were left at room temperature for 5 minutes and the colour change was read at the wavelength $405 \mathrm{~nm}$ and $450 \mathrm{~nm}$ with the difference recorded. The absorbance reading at $405 \mathrm{~nm}$ was subtracted from that at $450 \mathrm{~nm}$ to correct for interference from hexoses. The results were expressed as milligram of $\mathrm{GA} \mathrm{g}^{-1}$ of AIS.

\subsection{Total RNA isolation, and real-time quantitative polymerase chain reaction (RT- qPCR)}

Total RNA was extracted from finely powdered pericarp of tomato fruits at $0,7,14,21$ and $28 \mathrm{DAH}$ intervals using PureLink ${ }^{\mathrm{TM}}$ Plant RNA Reagent (Thermo Fisher Scientific) in accordance with the manufacturer's instructions. The RNA concentration was quantified using the NanoDrop (BioTek, Epoch Microplate) and reverse transcribed into cDNA by the RevertAid First Strand cDNA Synthesis Kit (Thermo Fisher Scientific). Relative expression of each gene was normalized to that of the endogenous reference gene elongation factor 1- $\alpha$ (Pokalsky et al., 1989) The primer sequences for the RT-qPCR are listed in Table 1. The thermal program for PCR was set using the following conditions: $95^{\circ} \mathrm{C}$ for $5 \mathrm{~min}, 35$ cycles of amplification of $5 \mathrm{~s}$ at $95^{\circ} \mathrm{C}, 30 \mathrm{~s}$ at $60^{\circ} \mathrm{C}, 30 \mathrm{~s}$ at $72^{\circ} \mathrm{C}$ using the $\mathrm{CFX96}^{\mathrm{TM}}$ Real-Time System (Bio-Rad). The gene expression levels were calculated using the $2^{-\Delta \Delta C t}$ method (Livak and Schmittgen, 2001).

\subsection{Determination of proline content}

The proline content was determined as described by (Wang et al., 2016). Briefly, $1 \mathrm{~g}$ of frozen powdered tomato pericarp tissue was homogenized in $1 \mathrm{~mL}$ of $3 \%(\mathrm{v} / \mathrm{v})$ sulfosalicylic acid and centrifuged at $12000 \mathrm{~g}$ for $10 \mathrm{~min}$ at $4^{\circ} \mathrm{C}$. $400 \mu \mathrm{L}$ supernatant was then mixed with $400 \mu \mathrm{L}$ glacial acetic acid and $400 \mu \mathrm{L}$ acidic ninhydrin reagent and boiled for $30 \mathrm{~min} ; 800 \mu \mathrm{L}$ toluene was then added to the reaction mixture. The absorbance was recorded at $520 \mathrm{~nm}$. Known proline concentrations were used to prepare standard curves. The results were expressed as $\mu \mathrm{g} \mathrm{g}^{-1} \mathrm{DW}$.

\subsection{Statistical analyzes}

The statistical analyzes were conducted according to completely randomized design with at least five different tomato fruits for fruit firmness and 10 fruits $\mathrm{Cl}$ measurements. Three different fruits were used for cell wall and gene expression analysis. Data presented are the means \pm SD values. Student's $t$ - test, at $p<0.05$ in SPSS 23.0. was performed to analyze the level of significance between the analyzed parameters.

\section{Results and Discussion}

GABA can accumulate rapidly under biotic and abiotic stress conditions and take part in the defense system against those conditions (Shelp et al., 1999). Accumulation of GABA has been reported in response to low $\mathrm{O}_{2}$ storage in tomatoes (Deewatthanawong et al., 2010). In our study, tomato samples were harvested at MG stage, treated with two different GABA concentration, and stored for 28 days at room temperature. Phenotypic variations in ripening tomato fruits after treatment with control, $5 \mathrm{mM}$ and $20 \mathrm{mM}$ of GABA are shown (Figure 1). Although all treated and non-treated fruits showed signs of softening and decomposition at $28 \mathrm{DAH}$, the fruits treated with $5 \mathrm{mM}$ of GABA appeared to have a better texture integrity compared to $20 \mathrm{mM}$ GABA treatment and control fruits (Figure 1).

Table 1. Primer sequences used for RT-qPCR

\begin{tabular}{lll}
\hline Gene & Forward sequence & Reverse sequence \\
\hline SIPG & AAGACTTGGCAGGGAGGATC & TATGGCCACCTTTGTTGCAC \\
SIPL & GCGATCAGGAGTTAGAACTGG & AATCCCCTTTTGCTTTGGTT \\
SIACS2 & TATGGAGAGTTATTATAAACGA & CTAAGTACATAGACCAGTTGTCA \\
SIACS4 & ATTCACTAGAGGACTTGAAGA & CAAGCTTTATAACTTTATTTGAT \\
LEEF-1 & ACCTTTGCTGAATACCCTCCATTG & CACAGTTCACTTCCCCTTCTTCG \\
\hline
\end{tabular}




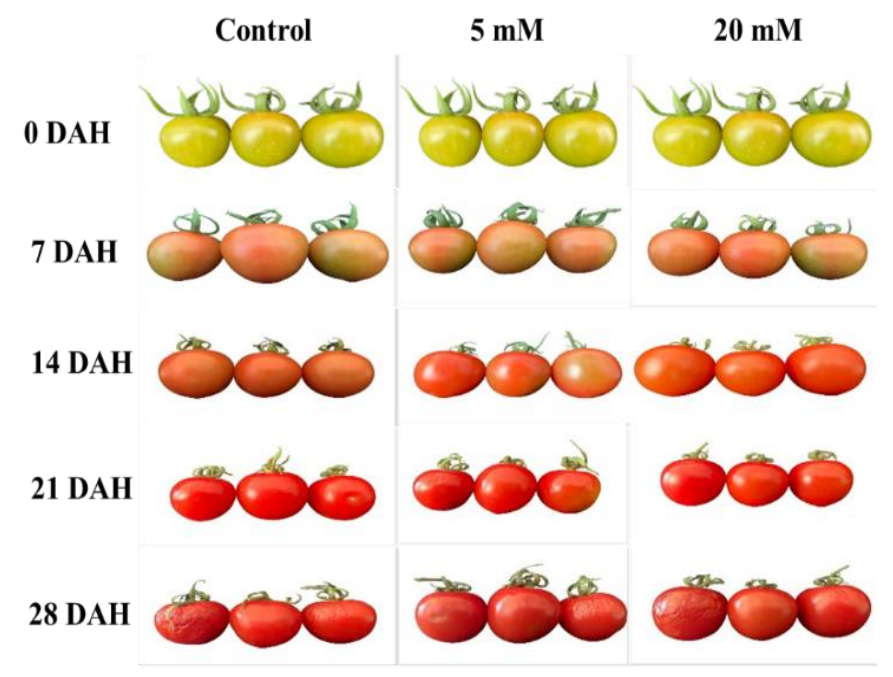

Figure 1. Photographs of tomato fruits treated with GABA taken in seven days intervals (DAH: days after harvesting).

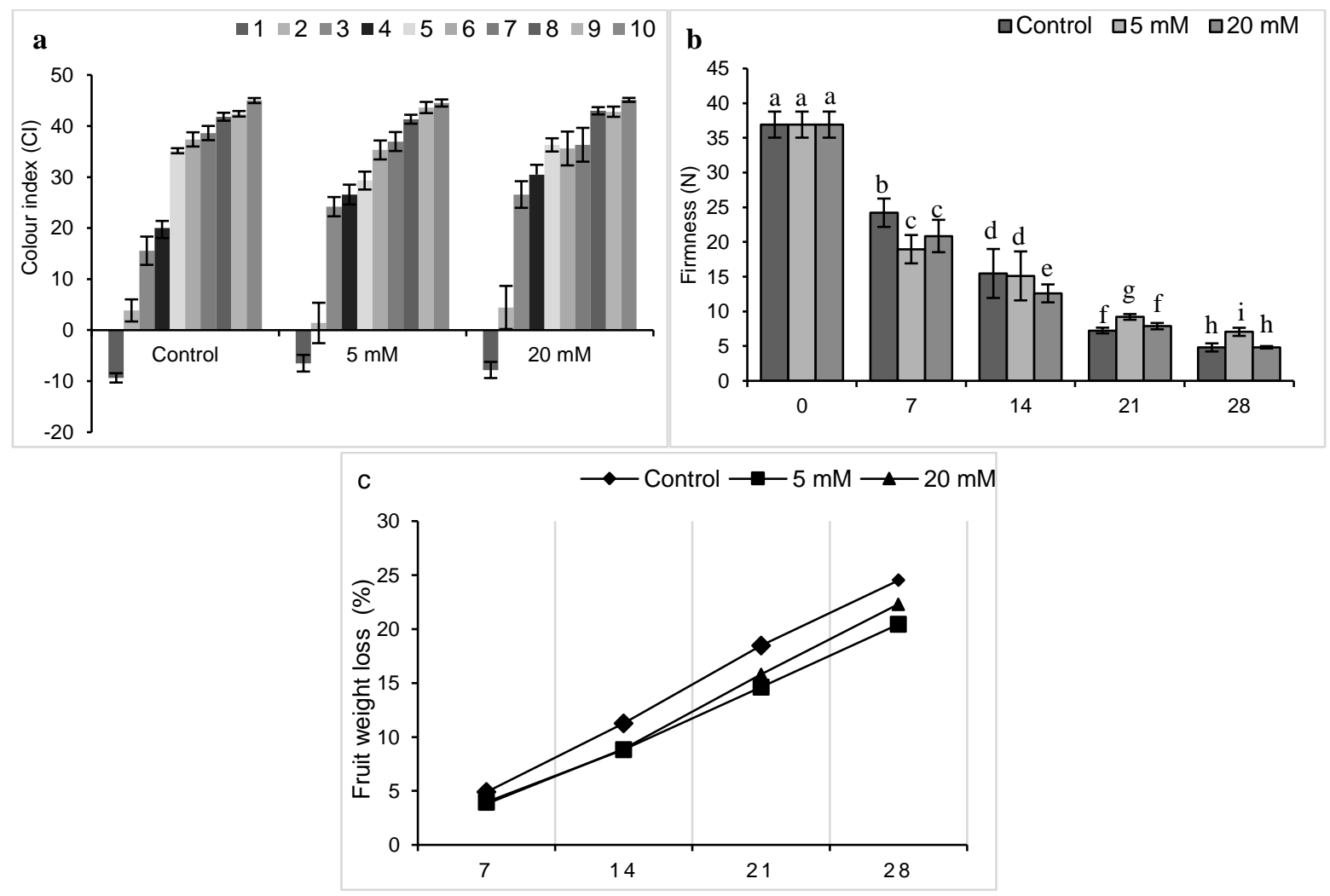

Figure 2. Effect of GABA treatment on $\mathrm{Cl}$ (a), firmness (b) and Fruit weight loss (FWL) (c) during post-harvest for 28 days. Data are mean \pm standard deviation (SD) of ten for $\mathrm{Cl}$ and five for firmness and $\mathrm{FWL}$ independent fruits.

Different letters on top of columns indicate statistically significant differences $p \leq 0.05$.

The colour index $(\mathrm{Cl})$ values of fruits increased sharply in the first four measurements (Figure 2a), which can also be seen $7 \mathrm{DAH}$ and $14 \mathrm{DAH}$ fruits (Figure 1). However, there was no statistical difference in $\mathrm{Cl}$ values at the end of post-harvest storage $(p>0.12)$.

Firmness is one of the important quality characteristics of fruits which increases their storage potential and provide resistance to diseases and mechanical damage. However, as the ripening progresses, customer acceptance, and marketability of tomato decrease (Distefano et al.,
2020). The changes in fruit firmness between control and GABA treated samples stored for 28 days are shown in Figure $2 \mathrm{~b}$. The firmness of all fruits treated or non-treated decreased during the storage. Although control fruits at $7 \mathrm{DAH}$ stage were firmer than the GABA-treated fruits, the tomato fruits treated with $5 \mathrm{mM}$ GABA resulted in statistically significant firmness towards the end of storage. In a previous study, Mature-green mango fruits were collected and treated with 50,100- and exogenous GABA. $200 \mathrm{mM}$ of GABA treatment led to better preservation of firmness of mango fruits (Rastegar 
et al., 2020). In another study, the fruit bodies of mushroom samples were immersed in $0.01,0.1$, 1.0 , or $10.0 \mathrm{mM}$ of GABA solution. The results showed that cap browning and weight loss were lower in $0.1 \mathrm{mM}$ GABA treated samples, which retained their firmness better than untreated mushrooms. (Shekari et al., 2021). Based on these results, it can be said that maximum quality and shelf-life in different fruit samples can be achieved by different GABA concentrations.

Evaporation of water from the fruit surface, respiration and metabolic activities cause weight loss during post-harvest storage in fruits. In other words, weight loss in fresh fruit causes fruit softening, ripening, and aging (Bai et al., 2003). The weight loss of the control and GABA treated tomato fruits is shown (Figure 2c). FWL in fruits of all groups increased gradually as ripening progressed. However, the fruit samples treated with $5 \mathrm{mM}$ and $20 \mathrm{mM}$ of GABA presented lower weight loss than that of the control fruits. Post-harvest treatments have minimized the weight loss of mushrooms (Shekari et al., 2021), tomatoes (Makino et al., 2008) and peaches (Shang et al., 2011). The difference in weight loss of fruits is due to the different permeability, chemical properties and applied GABA concentrations.

It is commonly known that loss of firmness and softening in fruits are directly related to changes in cell wall composition especially in pectic polysaccharides. In order to demonstrate the cell wall composition that accounts for differences in fruit firmness, the pericarps of GABA treated, and non-treated fruits were fractionated. A variety of differences in WSP levels at different ripening/softening stages were revealed (Figure 3). The WSP content was the highest in all groups at 14 days of storage. However, the amount of WSP started to decrease in fruits from the $14^{\text {th }}$ day of storage, and the least amount of WSP was obtained in tomatoes treated with $5 \mathrm{mM} \mathrm{GABA}$ in all periods. Contrary to the amount of WSP, the amount of $\mathrm{Na}_{2} \mathrm{CO}_{3}$ (covalently bound pectin) soluble pectin decreased as maturation increased. There was significantly higher amount of $\mathrm{Na}_{2} \mathrm{CO}_{3}$ soluble pectin in $5 \mathrm{mM}$ GABA treated fruits compared to the control and $20 \mathrm{mM}$ groups.

The cell wall composition change is the result of the coordinate action of cell wall degrading enzymes, including PL and PG (Brummel and Harpster, 2001). In our study, the transcript levels of two main cell wall-related genes are illustrated in Figure 4. At day 7 and 14, the expression of SIPL was reduced to half the level of control samples, especially in $14 \mathrm{DAH}$ fruits. $5 \mathrm{mM}$ of GABA treatment slightly downregulated the gene expression of SIPG at 21 and $28 \mathrm{DAH}$ stage. In general, as the storage time prolonged, SIPG and
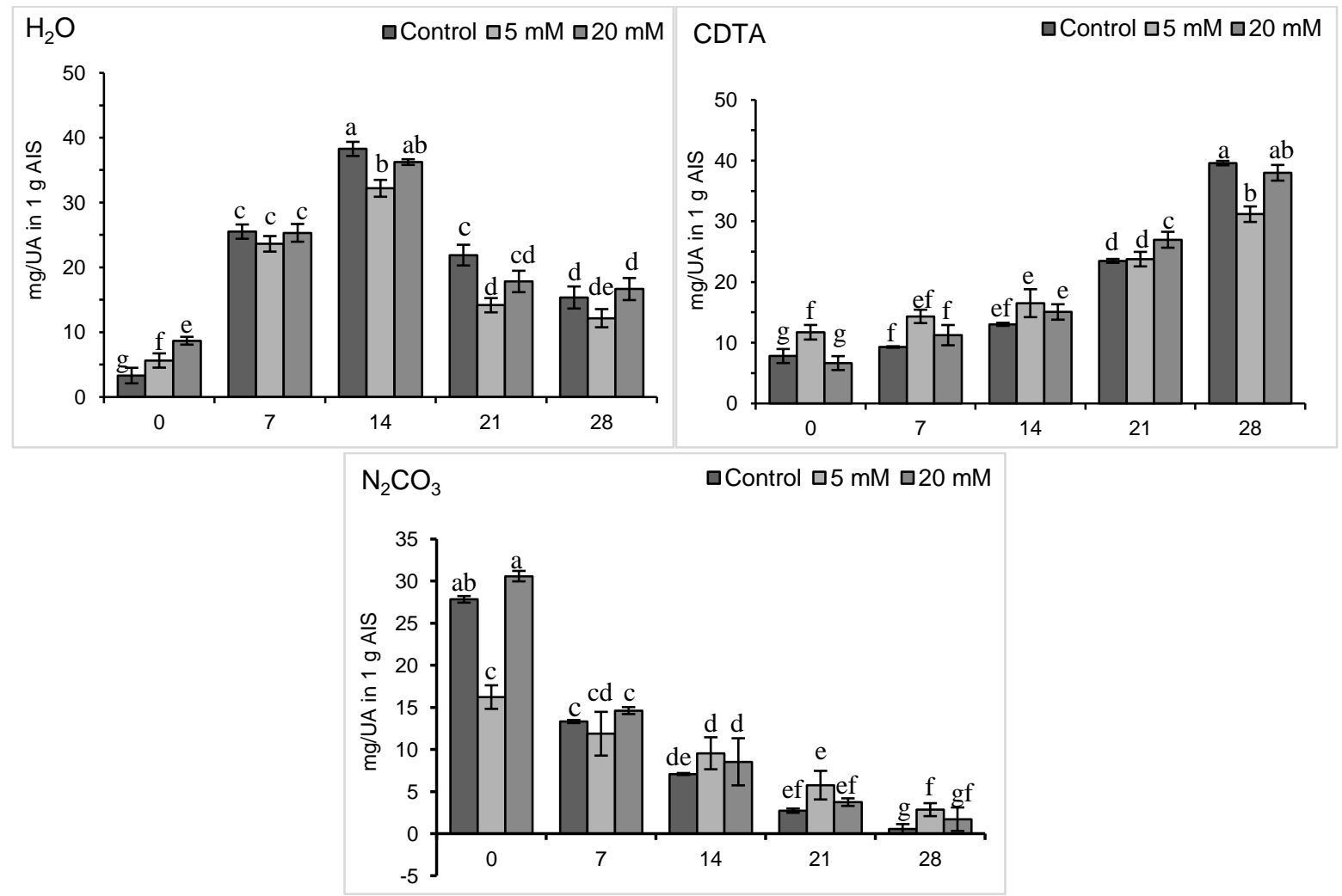

Figure 3. Effect of GABA treatments on WSP, CDTA and $\mathrm{Na}_{2} \mathrm{CO}_{3}$ soluble pectin contents.

Data are mean \pm standard deviation (SD) of three fruits at each stage and treatments.

Different letters indicate statistically significant differences $p \leq 0.05$. 


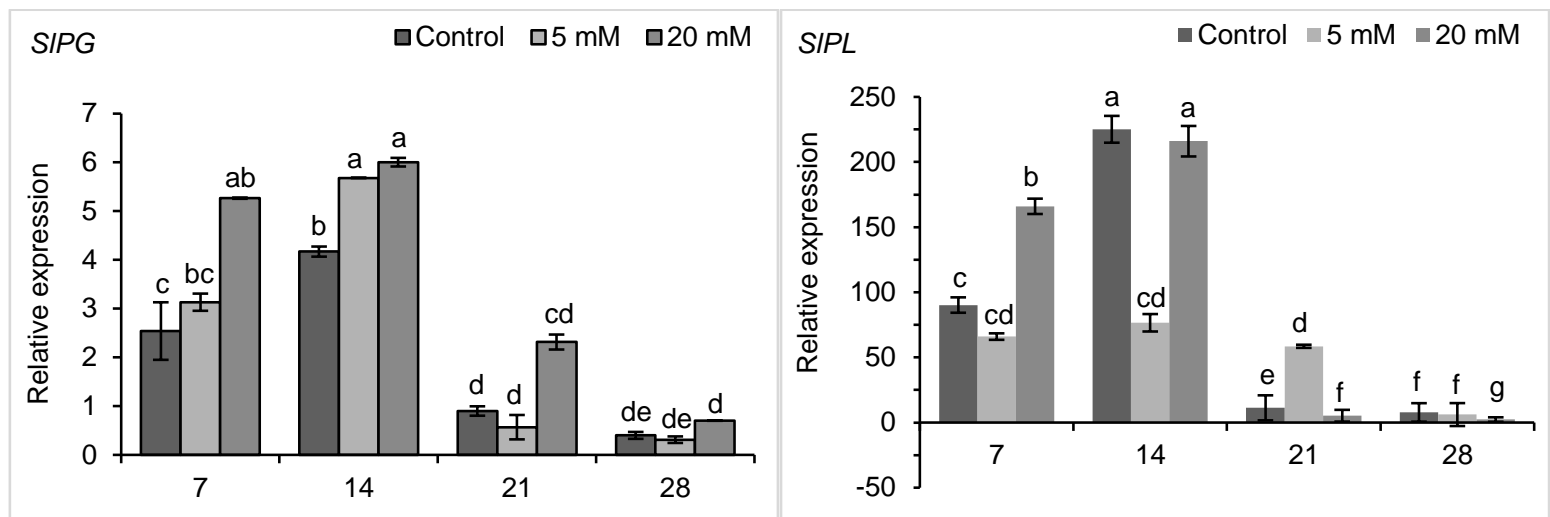

Figure 4. Expression pattern of genes involved in cell wall degradation in fruit ripening process.

The fold change of the genes was normalized compared to control group for each week.

The error bars on each column indicate the \pm SD of three biological and two technical replicates.

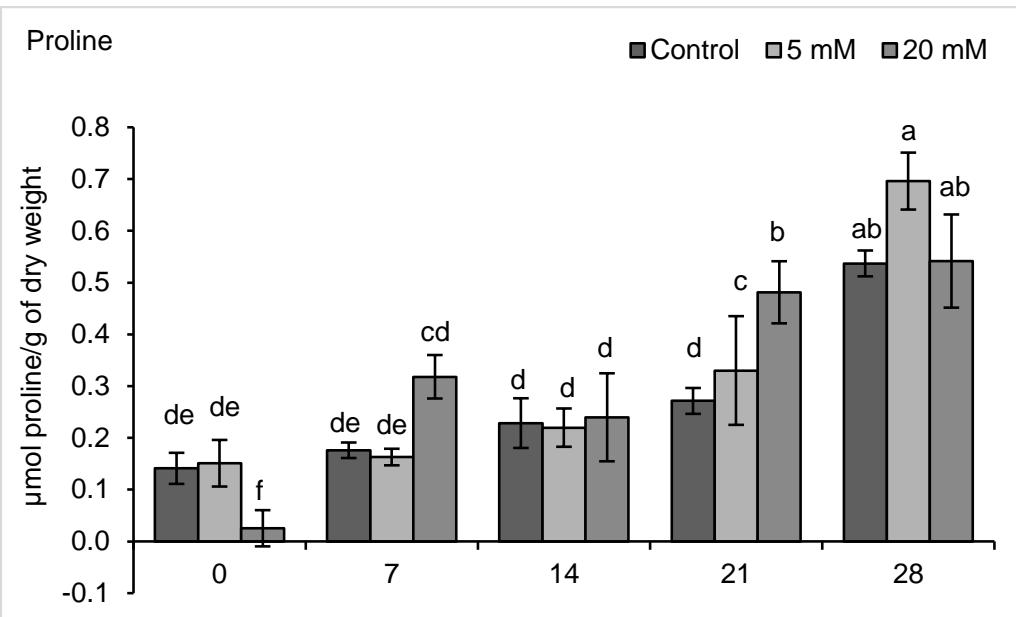

Figure 5. Effect of GABA treatments on proline contents of tomato fruits.

Data are mean \pm standard deviation (SD) of three fruits at each stage and treatments.

Different letters indicate statistically significant differences $p \leq 0.05$.

SIPL mRNA gradually decreased in all groups. However, a slightly more decrease in $5 \mathrm{mM}$ of GABA treated fruits, could be an increased fruit firmness in this group of fruits. These results indicated that $5 \mathrm{mM}$ of GABA treatment decreased the amount of WSP and expression of cell wall related genes, which delayed softening of tomato fruits under post-harvest storage conditions.

Proline is an important amino acid that has been shown to play an important role in the response of fruits to stress factors as it is an ROS, that can protect cells from damage with its antioxidant effect (Wei et al., 2019). Proline accumulation increased during the exposure of plants to various environmental stresses such as chilling (Gao et al., 2016), low temperature (Mohammadrezakhani et al., 2019) and drought (Antoniou et al., 2017). In our study, a significantly higher proline content was recorded in tomato fruits treated with $5 \mathrm{mM}$ of GABA in 28 DAH fruits $(p \leq 0.014)$ (Figure 5). Exogenous GABA treatment enhanced the accumulation of proline and increased resistance against chilling stress (Shang et al., 2011). Another similar study was reported that efficient control of chilling in cherry tomato fruit was associated with enhanced proline accumulation (Zhang et al., 2010). These results indicated that, an optimum concentration of GABA, $5 \mathrm{mM}$ of GABA in here, may be partly related to the increase in proline content and delayed postharvest softening.

An increase in ethylene production and respiration rate was observed at the beginning of climacteric tomato fruit ripening. Ethylene synthesis in ripening tomato fruit is regulated by 1aminocyclopropane-1-carboxylate synthase (ACS) and 1-aminocyclopropane-1-carboxylate oxidase (ACO) gene families (Barry et al., 2000). ACS2 and ACS4 mediate the burst of autocatalytic ethylene synthesis, a process typically observed in climacteric ripening (Barry et al., 2000). Ethylene production and respiration rate in GABA treated and control fruits had the similar pattern and the climacteric peak of all fruits emerged at $7 \mathrm{DAH}$ fruits, but the climacteric peaks of the $5 \mathrm{mM}$ GABA treated fruits were clearly lower than those of the control and $20 \mathrm{mM}$ GABA treated fruits (Figure $6 \mathrm{a}$ and $b$ ). We also detected the relative mRNA levels of the genes related to ethylene biosynthesis. Consistent with the climacteric peak and production of ethylene, the expression levels of SIACS2 and 

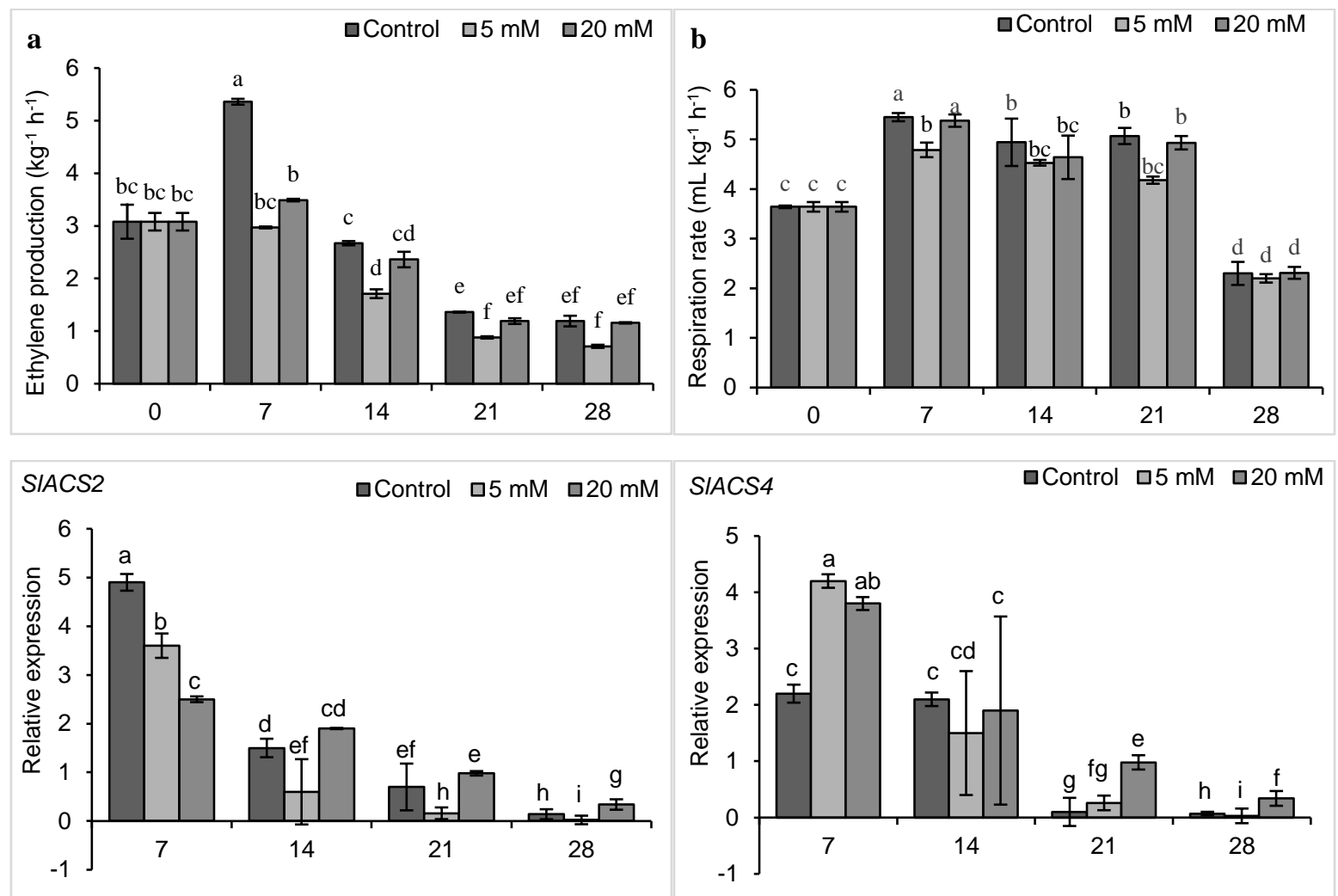

Figure 6. Effect of GABA treatments on respiration rate (a) and ethylene production (b) and ethylene synthesis related genes SIACS2/4 of tomato fruits during post-harvest storage at room temperature up to 28 days.

Data are mean \pm standard deviation (SD) of five fruits at each stage.

Different letters indicate statistically significant differences $p \leq 0.05$

SIACS4 were significantly enhanced at 7 DAH fruits (Figure 6). However, the expression of both genes was significantly suppressed in $5 \mathrm{mM}$ GABA treated fruits in the progress of storage. A value of $10 \mathrm{mM}$ of GABA treatment not only reduced the respiratory rate but also inhibited the ethylene production in apple fruits. Moreover, the expression levels of $M d A C O, M d A C S$ and MdERF were restricted to varying degrees by $10 \mathrm{mM}$ GABA treatment; this revealed that GABA participates in the regulation of ethylene biosynthesis and signal transduction at the molecular level (Han et al., 2018). It was recently suggested that higher fruit firmness in response to GABA may result directly from GABA treatment or indirectly from lower ethylene biosynthesis or higher level of cell wall hydrolysing enzymes such as PG and PL.

\section{Conclusion}

The results of the present study indicated that different concentrations of GABA had different effects on tomato quality undur post-harvest storage conditions. A concentration of $20 \mathrm{mM}$ of GABA accelerated fruit softening, fruit weight loss, increased WSP and the expression of cell wall degrading enzymes, suggesting that $20 \mathrm{mM}$ of exogenous GABA treatment is not a suitable concentration for increasing tomato quality parameters in post-harvest storage. The study shed lights on the favourable effects of $5 \mathrm{mM}$ GABA treatment on tomato fruit quality by increasing fruit firmness and shelf life and decreasing the expression of cell wall related genes and dissolution of pectic polysaccharides.

\section{References}

Aghdam, M.S., Kakavand, F., Rabiei, V., Nahandi, F.Z., \& Razavi, F. (2019). y-Aminobutyric acid and nitric oxide treatments preserve sensory and nutritional quality of cornelian cherry fruits during post-harvest cold storage by delaying softening and enhancing phenols accumulation. Scientia Horticulturae, 246:812-817.

Antoniou, C., Chatzimichail, G., Xenofontos, R., Pavlou, J.J., Panagiotou, E., Christou, A., \& Fotopoulos, V. (2017). Melatonin systemically ameliorates drought stress-induced damage in Medicago sativa plants by modulating nitro-oxidative homeostasis and proline metabolism. Journal of Pineal Research, 62(4).

Bai, J., Alleyne, V., Hagenmaier, R.D., Mattheis, J.P., \& Baldwin, E.A. (2003). Formulation of zein coatings for apple (Malus domestica Borkh). Post-harvest Biology and Technology, 28:259-268.

Barry, C.S., Llop-Tous, M.I., \& Grierson, D. (2000). The regulation of 1-aminocyclopropane-1-carboxylic acid synthase gene expression during the transition from system-1 to system-2 ethylene synthesis in tomato. Plant Physiology, 123:979-986.

Brummel, D.A., \& Harpster, M.H. (2001). Cell wall metabolism in fruit softening, quality, and its 
manipulation in transgenic plants. Plant Molecular Biology, 47:311-339.

Candir, E., Candir, A., \& Sen, F. (2017) Effects of aminoethoxyvinylglycine treatment by vacuum infiltration method on post-harvest storage and shelf life of tomato fruit, Post-harvest Biology and Technology, 125:13-25.

Chen, Y.H., Hung, Y.C., Chen, M.Y., Lin, M.S., \& Lin, H.T. (2019). Enhanced storability of blueberries by acidic electrolyzed oxidizing water application may be mediated by regulating ROS metabolism. Food Chemistry, 270:229-235.

Decros, G., Baldet, P., Beauvoit, B., Stevens, R., Flandin, A., Colombié, S., Gibon, Y., \& Pétriacq, P. (2019). Get the balance right: ROS homeostasis and redox signalling in fruit. Frontiers in Plant Science, 10:1091.

Deewatthanawong, R., Rowell, P., \& Watkins, C.B. (2010). Y-Aminobutyric acid (GABA) metabolism in $\mathrm{CO}_{2}$ treated tomatoes. Post-harvest Biology and Technology, 57:97-105.

Distefano, M., Arena, E., Mauro, R.P., Brighina, S., Leonardi, C., Fallico, B., \& Giuffrida, F. (2020). Effects of genotype, storage temperature and time on quality and compositional traits of cherry tomato. Foods, 9:1729.

Filisetti-Cozzi, T.M.C.C., \& Carpita, N.C. (1991). Measurement of uronic acids without interference from neutral sugars. Analytical Biochemistry, 197:157-162.

FAO. (2019). Food And Agriculture Organization of the United Nation. http://www.fao.org/faostat/en/\#home (Accessed date: 1 March, 2020).

Foyer, C.H. (2018). Reactive oxygen species, oxidative signaling and the regulation of photosynthesis. Environmental and Experimental Botany, 154:134142.

Gao, H., Zhang, Z., Lv, X. G., Cheng, N., Peng, B.Z., \& Cao, W. (2016). Effect of 24-epibrassinolide on chilling injury of peach fruit in relation to phenolic and proline metabolisms. Post-harvest Biology and Technology, 111:390-397.

Giovannoni, J.J. (2007). Fruit ripening mutants yield insights into ripening control. Current Opinion in Plant Biology, 10:283-289.

Han, S., Nan, Y., Qu, W., He, Y., Ban, Q., Lv, Y., \& Rao J. (2018). Exogenous $\mathrm{Y}$-Aminobutyric acid treatment that contributes to regulation of malate metabolism and ethylene synthesis in apple fruit during storage. Journal of Agricultural and Food Chemistry, 66:13473-13482.

Kinnersley, A.M., \& Turano, F.J. (2000). y-Aminobutyric acid (GABA) and plant responses to stress Critical Reviews in Plant Sciences, 19:479-509.

Klee, H.J., \& Giovannoni, J.J. (2011). Genetics and control of tomato fruit ripening and quality attributes Annual Review of Genetics, 45:41-59.

Li, J., Zhou, X., Wei, B., Cheng, S., Zhou, Q., \& Ji, S. (2019). GABA application improves the mitochondrial antioxidant system and reduces peel browning in 'Nanguo' pears after removal from cold storage. Food Chemistry, 297:124903

Lin, Y., Lin, Y., Lin, H., Lin, M., Li, H., Yuan, F., Chen, Y. \& Xiao, J. (2018) Effects of paper containing 1-MCP post-harvest treatment on the disassembly of cell wall polysaccharides and softening in Younai plum fruit during storage. Food Chemistry, 264:1-8.

Lin, Y.X., Lin, H.T., Chen, Y.H., Wang, H., Lin, M.S., \& Ritenour, M.A. (2020). The role of ROS-induced change of respiratory metabolism in pulp breakdown development of longan fruit during storage. Food Chemistry, 305:125439.

Livak, K.J., \& Schmittgen, T.D. (2001). Analysis of relative gene expression data using real-time quantitative $\mathrm{pcr}$ and the 2 CT method. Methods, 25:402-408.

Lunn, D., Phan, T.D., Tucker, G.A., \& Lycett, G.W. (2013). Cell wall composition of tomato fruit changes during development and inhibition of vesicle trafficking is associated with reduced pectin levels and reduced softening. Plant Physiology and Biochemistry, 66:9197.

Makino, Y., Soga, N., Oshita, S., Kawagoe, Y., \& Tanaka, A., (2008). Stimulation of $Y$-aminobutyric acid production in vine-ripe tomato (Lycopersicon esculentum Mill.) fruits under modified atmospheres. Journal of Agricultural and Food Chemistry, 56:7189. 7193.

Malekzadeh, P., Khara, J., \& Heydari, R. (2014) Alleviating effects of exogenous Gamma-aminobutiric acid on tomato seedling under chilling stress. Physiology and Molecular Biology of Plants, 20:133137.

Mansourbahmani, S., Ghareyazie, B., Zarinnia, V., Kalatejari, S., \& Mohammadi, R.Z. (2018). Study on the efficiency of ethylene scavengers on the maintenance of post-harvest quality of tomato fruit. Journal of Food Measurement and Characterization, 12:691-701.

Mohammadrezakhani, S., Hajilou, J., Rezanejad, F., \& Nahandi, F.Z. (2019). Assessment of exogenous application of proline on antioxidant compounds in three Citrus species under low temperature stress. Journal of Plant Interactions, 14:347-358.

Nangare, D.D., Singh, Y., Kumar, P.S., \& Minhas, P.S., (2016). Growth, fruit yield and quality of tomato (Lycopersicon esculentum Mill.) as affected by deficit irrigation regulated on phenological basis. Agricultural Water Management, 171:73-79.

Nazoori, F., Zamani Bahramabadi, E., \& Mirdehghan, S.H. (2020). Extending the shelf life of pomegranate (Punica granatum L.) by GABA coating application. Food Measure, 14: 2760-2772.

Niazi, Z., Razavi, F., Khademi, O., \& Aghdam, M.S. (2021). Exogenous application of hydrogen sulfide and $y$-aminobutyric acid alleviates chilling injury and preserves quality of persimmon fruit (Diospyros kaki, cv. Karaj) during cold storage. Scientia Horticulturae, 285:110198.

Park, M.H., Kim, S.J., Lee, J.S., Hong, Y.P., Chae, S.H., \& Ku, K.M. (2021). Carbon dioxide pre-treatment and cold storage synergistically delay tomato ripening through transcriptional change in ethylene-related genes and respiration-related metabolism. Foods, 10:744.

Pokalsky, A.R., Hiatt, W.R., Ridge, N., Rasmussen, R., \& Shewmaker, C. K. (1989) Structure and expression of elongation factor $1 \alpha$ in tomato. Nucleic Acids Research, 17:4666-4673.

Rastegar, S., Khankahdani, H.H., \& Rahimzadeh, M. (2020). Effect of $Y$-aminobutyric acid on the antioxidant system and biochemical changes of mango fruit during storage. Food Measure, 14:778789.

Seymour, G.B., Chapman, N.H., Chew, B.L., \& Rose, J.K. C. (2013). Regulation of ripening and opportunities for control in tomato and other fruits. Plant Biotechnology Journal, 11:269-278.

Shang, H.T., Cao, S.F., Yang, Z.F., Cai, Y.T., \& Zheng, Y.H. (2011). Effect of exogenous $Y$-aminobutyric acid 
treatment on proline accumulation and chilling injury in peach fruit after long-term cold storage. Journal of Agricultural and Food Chemistry, 59:264-1268.

Shekari, A., Hassani, R.N., \& Aghdam, M.S. (2021). Exogenous application of GABA retards cap browning in Agaricus bisporus and its possible mechanism. Post-harvest Biology and Technology, 174:111434.

Shelp, B.J., Bown, A.W., \& McLean, M.D. (1999). Metabolism and functions of gamma-aminobutyric acid. Trends in Plant Sciences, 4:446-452.

Soleimani Aghdam, M., Naderi, R., Jannatizadeh, A., Sarcheshmeh, M.A., \& Babalar, M. (2016) Enhancement of post-harvest chilling tolerance of anthurium cut flowers by $\mathrm{Y}$-aminobutyric acid (GABA) treatments. Scientia Horticulturae, 198:52-60.

Uluisik, S., Chapman, N.H., Smith, R., Poole, M., Adams, G., Gillis, R.B., Besong, T.M., Sheldon, J., Stiegelmeyer, S., Perez, L., Samsulrizal, N., Wang, D., Fisk, I.D., Yang, N., Baxter, C., Rickett, D., Fray, R., Blanco-Ulate, B., Powell, A.L., Harding, S.E., Craigon, J., Rose, J.K., Fich, E.A., Sun, L., Domozych, D.S., Fraser, P.D., Tucker, G.A., Grierson, D., \& Seymour, G.B. (2016). Genetic improvement of tomato by targeted control of fruit softening. Nature Biotechnology, 34:950-2.

Wang, D., Yeats, T.H., Uluisik, S., Rose, J.K.C., \& Seymour, G.B. (2018). Fruit Softening: Revisiting the Role of Pectin. Trends in Plant Science, 23:302-310.
Wang, Y., Luo, Z., Mao, L., \& Ying, T. (2016). Contribution of polyamines metabolism and GABA shunt to chilling tolerance induced by nitric oxide in cold-stored banana fruit. Food Chemistry, 197:333-339.

Wei, C., Ma, L., Cheng, Y., Guan, Y., \& Guan, J. (2019). Exogenous ethylene alleviates chilling injury of 'Huangguan' pear by enhancing the proline content and antioxidant activity. Scientia Horticulturae, 257:208671.

Yan, M.A., Duan, S., \& Zhao, M. (2016). Research progress of foods rich in gamma-aminobutyric acid. Biotic Resources, 38:1-6.

Zarei, L., Saba, M.K., \& Vafaee, Y. (2020). Effect of gamma-amino-butyric acid (GABA) foliar application on chilling and post-harvest quality of tomato (cv. Newton). Plant Productions, 43:199-212.

Zhang, X.H., Shen, L., Li, F.J., Zhang, Y.X., Meng, D.M., \& Sheng, J.P. (2010). Up-regulating arginase contributes to amelioration of chilling stress and the antioxidant system in cherry tomato fruits. Journal of the Science of Food and Agriculture, 90:2195-2202.

Zhong, T.Y., Yao, G.F., \& Wang, S.S. (2021). Hydrogen sulfide maintains good nutrition and delays postharvest senescence in post-harvest tomato fruits by regulating antioxidative metabolism. Journal of Plant Growth Regulation. https://doi.org/10.1007/s00344021-10377-4 